\title{
Distress and Glycemic Control in Patients with Diabetes Mellitus with Co-Morbid Depression
}

\author{
Dr. Malika Jindal ${ }^{1}$, Dr. Geet Bagri ${ }^{2}$, Dr. Navkiran S. Mahajan, M.D Psychiatry ${ }^{3 *}$
}

${ }^{1,2}$ PG Resident Psychiatry, DMC\&H, Ludhiana, India

${ }^{3}$ Professor, DMC\&H, Ludhiana, India

DOI: $10.36347 /$ sjams.2020.v08i07.019

| Received: 10.07.2020 | Accepted: 17.07.2020 | Published: 21.07.2020

*Corresponding author: Dr. Navkiran S. Mahajan

\section{Abstract}

Original Research Article

Background: Co-occurrence of Diabetes Mellitus and Depressive Disorder has become a major health concern in today's world. Several studies have looked into correlation of Diabetes Distress and Depression with the glycemic control but there are very few longitudinal studies and findings are also inconsistent. Aim: To assess Diabetic Distress and Glycemic control in patients with Diabetes Mellitus. Material and methods: The clinical study was conducted on 100 patients. 50 patients with Diabetes Mellitus and Depression in case group and 50 patients with Diabetes Mellitus in control group were included. Diabetes Distress was assessed by 17-item Diabetes Distress Scale. Glycemic control was assessed by routine HbA1C investigations. Depressive Disorder was assessed by 21 - item Hamilton rating scale for Depressive symptoms and severity. Patients were assessed at baseline and 6 months. Results: Poor glycemic control was associated with higher Diabetes Distress (especially emotional burden and regimen related Distress) among both the groups at baseline and 6 months (p-value<0.005). Improvement in the glycemic control in both the groups was associated with the reduction in Diabetes Distress (p-value $=0.000$ ). There was no significant difference between the Diabetes Distress score among the two groups. There was no significant relationship between the glycemic control with HAM-D score at baseline but there was improvement in HAM-D score with improvement in the glycemic control ( $\mathrm{p}$-value=0.016). Conclusions: Better glycemic control improves the Diabetes Distress as well as HAM-D score.

Keywords: Diabetes Distress, Glycemic control, Depressive Disorder, Diabetes Mellitus

Copyright @ 2020: This is an open-access article distributed under the terms of the Creative Commons Attribution license which permits unrestricted use, distribution, and reproduction in any medium for non-commercial use (NonCommercial, or CC-BY-NC) provided the original author and source are credited.

\section{INTRODUCTION}

Diabetes Mellitus is one of the largest global health emergencies of the 21 st century. There are 415 million people living with Diabetes in the world and there will be 642 million people with Diabetes in the world in 2040. In India there are 69.2 million people with Diabetes [1]. As per World Health Organization the total number of people living with Depressive Disorder in the world is 322 million. The prevalence of Depressive Disorder in India is $4.5 \%$ as per World Health Organization [2].

Co-occurrence of Depressive Disorder and Diabetes Mellitus has become a major problem in every region of the world. Prevalence rate of Depressive Disorder is more than three times higher in people with type 1 Diabetes Mellitus and nearly twice as high in people with type 2 Diabetes Mellitus compared to those without [3]. The link between Depressive Disorder and type 2 Diabetes Mellitus is bidirectional: type 2 Diabetes Mellitus is associated with a roughly $20 \%$ increased risk of incidence of Depressive Disorder and Depressive Disorder is associated with a $60 \%$ increased risk of incidence of type 2 Diabetes Mellitus [4,5]. The combination of Diabetes Mellitus and Depressive Disorder present a major clinical challenge as the outcomes of both the conditions are worsened by the presence of the other.

Diabetes related Distress refers to the emotional burden that may be an aspect of managing a chronic illness, and can be found in both the patients with Diabetes Mellitus and their caregivers. It is different from the clinical experience of Depressive Disorder. High levels of Distress have been significantly linked to elevated HbA1c [6]. Prevalence of Diabetic Distress is 18-35\% [7].

Studies of the relationship between Depressive Disorder and glycemic control in adults have yielded discrepant findings. This study was conducted to find the co-relation between the Distress and glycemic 
control in patients with Diabetes Mellitus with comorbid Depressive Disorder.

\section{Methodology}

The clinical study was conducted on 100 patients. 2 groups were taken. First group including 50 patients having Diabetes Mellitus with co-morbid Depression and second group including 50 patients having Diabetes Mellitus was taken as control group who attended the Psychiatry and Endocrinology department indoor and/or outdoor patient department. The patients in age group 18-60 years and who had given informed consent were included in the study. The patients who had any serious organic illness or known case of any other major psychiatric illness were excluded from the study. Socio-demographic proforma containing the basic information about the patient were filled. Diabetes Distress was assessed by 17 item Diabetes Distress Scale. Glycemic control was assessed by routine HbA1C investigations. Depression was assessed by 21 item Hamilton rating scale for Depressive symptoms and severity. Patients were assessed at baseline and at 6 months.

\section{Stastical Analysis}

Demographic profile of both the case and control group patients was analysed by using t-test, chisquare test. Association between $\mathrm{HbA1C}$ levels and Diabetes Distress was analysed by ANOVA test. Association between HbA1C levels and HAM-D score was analysed by ANOVA test. Association between the HbA1C levels and Diabetes Distress from baseline to 6 months was analysed by Pearson correlation. Association between the HbA1C levels and HAM-D score from baseline to 6 months was analysed by Pearson correlation.

\section{RESULTS}

In the study two groups were taken. One case group $(n=50)$ in which $52 \%$ of patients were females and $48 \%$ were males and control group $(n=50)$ in which $40 \%$ were females and $60 \%$ were males. Mean age of patients in case group $(\mathrm{n}=50)$ was $49.02 \pm 7.18$ years and it was $48.82 \pm 8.93$ years in control group $(n=50)$. In case group $(n=50)$ majority of the patients $(36 \%)$ were educated upto below matriculation and in control group $(n=50)$ majority of the patients $(34 \%)$ were educated upto matriculation.
In the case group $(n=50) 4 \%$ of the patients were single, $92 \%$ of the patients were married and $4 \%$ of the patients were widowed or divorced. In the control group $(n=50) 2 \%$ of the patients were single and $98 \%$ of the patients were married. Majority of the patients between both the groups were married. In both the case and control group patient's majority of the patients were housewives. In case group patients $(n=50) 50 \%$ patients were housewives and in case of control group $(n=50)$ $38 \%$ patients were housewives. In both the groups majority of the patients had duration of illness between 2-8 years. In case group patients $(n=50) 18(36 \%)$ patients and in control group $25(50 \%)$ patients had duration of Diabetes Mellitus between 2-8 years.

Majority of the patients in both the groups had $\mathrm{HbA} 1 \mathrm{C}$ in range of $8-10 \%$. Among the case group $(\mathrm{n}=50), 18(36 \%)$ patients and in control group $(\mathrm{n}=50)$, $17(34 \%)$ patients had HbA1C levels within range of 8 $10 \%$. Majority of the patients between both the groups had $\mathrm{HbA} 1 \mathrm{C}$ in range of $6-8 \%$. Among case group $(n=50), 34(68 \%)$ patients and in control group $(n=50)$, $29(58 \%)$ patients had HbA1C in range of $6-8 \%$ at 6 months. There was significant relationship between the HbA1C levels and total DDS score, emotional burden score and regimen related Distress. Higher HbA1C levels were associated with higher levels of Diabetes Distress, emotional burden, regimen related Distress in both the case and control group patients at baseline and 6 months ( $\mathrm{p}$-value $<0.05$ ).

There is significant relationship between the DDS score and HBA1C from baseline to 6 months in both the groups (p-value<0.05). With the improvement in the Diabetes Distress there was improvement in the glycemic control or vice-versa.

There was no significant relationship between HbA1C and HAM-D score at baseline. The relationship between HbA1C levels and HAM-D score in case group patients at 6 months. There was significant relationship between HbA1C and HAM-D score at 6 months (pvalue $=0.010)$. With the improvement in the Depressive symptoms there was improvement in the HbA1C levels ( $p$-value $=0.016)$. This may be found because with the improvement in the Depressive symptoms there may be improved adherence to the prescribed Diabetes Mellitus treatment and improved self-care. There may be improved eating habits and physical activity. 
Table-1: Distribution of patients according to socio-demographic status

\begin{tabular}{|c|c|c|c|}
\hline 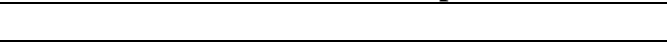 & CASE & CONTROL & p-value \\
\hline $\mathrm{AGE}$ & $49.02 \pm 7.18$ & $48.82 \pm 8.93$ & 0.902 \\
\hline SEX & & & 0.158 \\
\hline Male & $24(48 \%)$ & $30(60 \%)$ & \\
\hline Female & $26(52 \%)$ & $20(40 \%)$ & \\
\hline EDUCATION & & & 0.164 \\
\hline Illiterate & $8.0 \%$ & $2.0 \%$ & \\
\hline Below matriculation & $36.0 \%$ & $22.0 \%$ & \\
\hline Matriculate & $32.0 \%$ & $34.0 \%$ & \\
\hline Higher secondary & $10.0 \%$ & $12.0 \%$ & \\
\hline Graduate/ Post graduate & $14.0 \%$ & $30.0 \%$ & \\
\hline MARITAL STATUS & & & 0.297 \\
\hline Single & $4.0 \%$ & $2.0 \%$ & \\
\hline Married & $92.0 \%$ & $98.0 \% 0$ & \\
\hline Widowed/ Divorced & $4.0 \%$ & $0.0 \%$ & \\
\hline OCCUPATION & & & 0.456 \\
\hline Housewife/ household & $50.0 \%$ & $38.0 \%$ & \\
\hline Semiskilled/ Skilled & $12.0 \%$ & $16.0 \%$ & \\
\hline Shop owner & $6.0 \%$ & $12.0 \%$ & \\
\hline Farmer & $14.0 \%$ & $8.0 \%$ & \\
\hline Other & $18.0 \%$ & $26.0 \%$ & \\
\hline DURATION OFDIABETES MELLITUS & & & 0.241 \\
\hline 0-2 YEARS & $24.0 \%$ & $10.0 \%$ & \\
\hline 2-8 YEARS & $36.0 \%$ & $50.0 \%$ & \\
\hline 8-16 YEARS & $32.0 \%$ & $34.0 \%$ & \\
\hline MORE THAN 16 & $8.0 \%$ & $6.0 \%$ & \\
\hline OTHER CO-MORBIDITY & $18.0 \%$ & $28.0 \%$ & 0.235 \\
\hline FAMILY HISTORY OF MEDICAL ILLNESS & $50.0 \%$ & $62.0 \%$ & 0.227 \\
\hline FAMILY HISTORY OF PSYCHIATRIC ILLNESS & $10.0 \%$ & $6.0 \%$ & 0.357 \\
\hline
\end{tabular}

Table-2: Distribution of HBA1C levels at baseline and 6 months in case and control groups

\begin{tabular}{|c|c|c|c|c|c|c|}
\hline HBA1C & \multicolumn{2}{|c|}{ CASE } & \multicolumn{2}{|c|}{ CONTROL } & \multicolumn{2}{|l|}{ p-value } \\
\hline & BASELINE & 6 MONTHS & BASELINE & 6 MONTHS & BASELINE & 6 MONTHS \\
\hline $6-8 \%$ & $34.0 \%$ & $68.0 \%$ & $28.0 \%$ & $58.0 \%$ & \multirow{4}{*}{0.805} & \multirow{4}{*}{0.712} \\
\hline $8-10 \%$ & $36.0 \%$ & $26.0 \%$ & $34.0 \%$ & $32.0 \%$ & & \\
\hline $10-12 \%$ & $20.0 \%$ & $4.0 \%$ & $28.0 \%$ & $8.0 \%$ & & \\
\hline$>12 \%$ & $10.0 \%$ & $2.0 \%$ & $10.0 \%$ & $2.0 \%$ & & \\
\hline
\end{tabular}

Table-3: Distribution of case and control patients according to diabetes distress score at baseline and at 6 months

Table-3: Distribution of case and control patients according to diabetes distress score at baseline and at 6 months
\begin{tabular}{|c|l|l|l|l|c|c|}
\hline & CASE & \multicolumn{1}{l|}{ CONTROL } & p-value \\
\hline & BASELINE & 6 MONTHS & BASELINE & 6 MONTHS & BASELINE & 6 MONTHS \\
\hline Total DDS Score & $34.48 \pm 7.97$ & $29.12 \pm 6.88$ & $35.18 \pm 8.37$ & $28.88 \pm 6.37$ & 0.669 & 0.857 \\
\hline Emotional Burden & $17.14 \pm 4.80$ & $13.80 \pm 4.28$ & $15.94 \pm 4.82$ & $13.10 \pm 4.04$ & 0.215 & 0.402 \\
\hline Physician-related Distress & $4.12 \pm 0.63$ & $4.00 \pm 0.00$ & $4.48 \pm 1.37$ & $4.00 \pm 0.00$ & 0.095 & \\
\hline Regimen-related Distress & $10.30 \pm 3.48$ & $8.38 \pm 2.75$ & $11.78 \pm 3.81$ & $8.82 \pm 2.68$ & $0.045^{*}$ & 0.419 \\
\hline Interpersonal Distress & $3.00 \pm 0.00$ & $3.00 \pm 0.00$ & $3.00 \pm 0.00$ & $3.00 \pm 0.00$ & & \\
\hline
\end{tabular}

(p-value $<0.05) *$ significant

Table-4: Relationship between total DDS score with HBA1C in case and control group at baseline

\begin{tabular}{|c|c|c|c|c|c|c|c|c|c|c|}
\hline & \multicolumn{2}{|l|}{$6-8 \%$} & \multicolumn{2}{|l|}{$8-10 \%$} & \multicolumn{2}{|l|}{$10-12 \%$} & \multicolumn{2}{|l|}{$>12 \%$} & \multicolumn{2}{|l|}{ p-value } \\
\hline & case & Control & case & Control & case & Control & case & control & case & control \\
\hline $\begin{array}{l}\text { Total DDS } \\
\text { Score }\end{array}$ & $25.35 \pm 3.72$ & $26.93 \pm 5.05$ & $35.92 \pm 3.64$ & $35.88 \pm 6.10$ & $38.50 \pm 2.12$ & $39.36 \pm 7.65$ & 50.00 & $44.20 \pm 5.81$ & $0.000^{*}$ & $0.000 *$ \\
\hline $\begin{array}{l}\text { Emotional } \\
\text { Burden }\end{array}$ & $11.47 \pm 2.48$ & $11.93 \pm 3.20$ & $18.00 \pm 2.35$ & $16.94 \pm 3.90$ & $20.50 \pm 0.71$ & $17.64 \pm 5.39$ & 25 & $19.00 \pm 3.67$ & $0.000 *$ & $0.001 *$ \\
\hline $\begin{array}{l}\text { Physician } \\
\text { related Distress }\end{array}$ & $4.00 \pm 0.00$ & $4.00 \pm 0.00$ & $4.00 \pm 0.00$ & $4.29 \pm 1.21$ & $4.00 \pm 0.00$ & $4.79 \pm 1.72$ & 4.00 & $5.60 \pm 2.19$ & 0.434 & 0.106 \\
\hline $\begin{array}{l}\text { Regimen } \\
\text { related Distress }\end{array}$ & $7.00 \pm 1.58$ & $8.00 \pm 2.08$ & $10.85 \pm 1.72$ & $11.65 \pm 2.62$ & $11.00 \pm 1.41$ & $14.00 \pm 3.11$ & 18.00 & $16.60 \pm 2.88$ & $0.000^{*}$ & $0.000^{*}$ \\
\hline $\begin{array}{l}\text { Interpersonal } \\
\text { Distress }\end{array}$ & $3.00 \pm 0.00$ & $3.00 \pm 0.00$ & $3.00 \pm 0.00$ & $3.00 \pm 0.00$ & $3.00 \pm 0.00$ & $3.00 \pm 0.00$ & 3.00 & $3.00 \pm 0.00$ & & \\
\hline
\end{tabular}

$(\mathrm{P}$-value $<0.05) *$ significant 
Malika Jindal et al., Sch J App Med Sci, July, 2020; 8(7): 1741-1745

Table-5: Relationship between total DDS score and subscore with HBA1C in case and control group at 6 months

\begin{tabular}{|c|c|c|c|c|c|c|c|c|c|c|}
\hline & \multicolumn{2}{|l|}{ 6-8 } & \multicolumn{2}{|l|}{$8-10 \%$} & \multicolumn{2}{|l|}{$10-12 \%$} & \multicolumn{2}{|l|}{$>12 \%$} & \\
\hline & Case & Control & Case & Control & Case & Control & Case & Control & Case & Control \\
\hline Total DDS Score & $\begin{array}{l}25.35 \pm \\
3.72 \\
\end{array}$ & $\begin{array}{l}24.90 \pm \\
3.60 \\
\end{array}$ & $\begin{array}{l}35.92 \pm \\
3.64 \\
\end{array}$ & $32.94 \pm 4.74$ & $\begin{array}{l}38.50 \pm \\
2.12 \\
\end{array}$ & $\begin{array}{l}40.25 \pm \\
2.63 \\
\end{array}$ & 50.00 & 34.00 & $0.000^{*}$ & $0.000 *$ \\
\hline Emotional Burden & $\begin{array}{l}11.47 \pm \\
2.48\end{array}$ & $\begin{array}{l}10.86 \pm \\
2.33\end{array}$ & $\begin{array}{l}18.00 \pm \\
2.35\end{array}$ & $15.31 \pm 3.72$ & $\begin{array}{l}20.50 \pm \\
0.71\end{array}$ & $\begin{array}{l}20.25 \pm \\
1.89\end{array}$ & 25.00 & 14.00 & $0.000^{*}$ & $0.000^{*}$ \\
\hline Physician related Distress & $\begin{array}{l}4.00 \pm \\
0.00\end{array}$ & $\begin{array}{l}4.00 \pm \\
0.00\end{array}$ & $\begin{array}{l}4.00 \pm \\
0.00\end{array}$ & $\begin{array}{l}4.00 \pm \\
0.00\end{array}$ & $\begin{array}{l}4.00 \pm \\
0.00\end{array}$ & $\begin{array}{l}4.00 \pm \\
0.00\end{array}$ & 4.00 & 4.00 & . & \\
\hline Regimen related Distress & $\begin{array}{l}7.00 \pm \\
1.58 \\
\end{array}$ & $\begin{array}{l}7.14 \pm \\
1.71 \\
\end{array}$ & $\begin{array}{l}10.85 \pm \\
1.72 \\
\end{array}$ & $10.63 \pm 1.82$ & $\begin{array}{l}11.00 \pm \\
1.41 \\
\end{array}$ & $\begin{array}{l}12.75 \pm \\
1.50 \\
\end{array}$ & 18.00 & & $0.000 *$ & $0.000^{*}$ \\
\hline Interpersonal Distress & $\begin{array}{l}3.00 \pm \\
0.00\end{array}$ & $\begin{array}{l}3.00 \pm \\
0.00\end{array}$ & $\begin{array}{l}3.00 \pm \\
0.00\end{array}$ & $\begin{array}{l}3.00 \pm \\
0.00\end{array}$ & $\begin{array}{l}3.00 \pm \\
0.00\end{array}$ & $\begin{array}{l}3.00 \pm \\
0.00\end{array}$ & 3.00 & 3.00 & & \\
\hline
\end{tabular}

Table-6: Relationship of HbA1C with HAM-D score at baseline and 6 months

\begin{tabular}{|l|l|l|l|l|l|l|l|l|l|l|}
\hline & $\mathbf{6 - 8 \%}$ & $\mathbf{8 - 1 0 \%}$ & $\mathbf{1 0 - 1 2 \%}$ & \multicolumn{1}{l|}{ p-value } \\
\hline & Baseline & $6 \mathrm{mo}$ & baseline & $6 \mathrm{mo}$ & Baseline & $6 \mathrm{mo}$ & baseline & $6 \mathrm{mo}$ & baseline & 6 mo \\
\hline HAM-D score & $13.65 \pm$ & $9.00 \pm$ & $15.06 \pm$ & $7.77 \pm$ & $13.90 \pm$ & $16.50 \pm$ & $15.60 \pm$ & 11.00 & 0.666 & $0.010^{*}$ \\
& 4.29 & 2.97 & 4.32 & 3.06 & 3.25 & 9.19 & 4.51 & & & \\
\hline
\end{tabular}

$(\mathrm{P}-\mathrm{value}<0.05) *$ Significant

\section{DISCUSSION}

Co-occurrence of Diabetes Mellitus and Depressive Disorder has become a major problem in today's world. There is significant Diabetes Distress associated with Diabetes Mellitus. There are very few studies which have seen the association of Depressive Disorder and Diabetes Distress with the glycemic control and results are also discrepant. The present study looked into correlation of glycemic control with the Diabetes Distress and Depressive symptoms.

In our study there was significant difference in regimen related Distress between both the groups ( $\mathrm{p}$ value $=0.045$ ). At 6 months there was no significant difference between the two groups. This finding may be because that there was higher HbA1C levels and higher total Diabetes Distress score in the control group at baseline as higher Distress levels lead to more concern regarding the need of regular treatment, diet control and regular monitoring of blood sugar levels that lead to the higher HbA1C levels. Poor glycemic control also leads to higher levels of Diabetes Distress and regimen related Distress as poor glycemic control leads to need of frequent monitoring of blood glucose levels, need to follow the diet regime and to engage in physical activities, resulting in higher Distress levels showing the bi-directional relationship between the two [8]. Samantha Ramkisson et al. in a study conducted in South Africa stated that higher HbA1C contribute to the higher levels of Distress [9]. It was found in our study that the patients in both the groups who had higher levels of glycosylated haemoglobin had higher levels of Diabetes Distress especially emotional burden and regimen related Distress ( $p$-value $<0.05$ ) both at baseline and at 6 months.Similar findings were found in a study conducted by Wong et al. who found that higher HbA1C levels were associated with emotional burden $(p=0.03)$ and regimen-related Distress $(p=0.01)[10]$.
We found that Diabetes Distress was associated with the glycosylated haemoglobin at baseline and at 6 months in both the groups and there was improvement in Diabetes Distress with improvement in $\mathrm{HbA1C}$ levels from baseline to 6 months. There are many studies which have found similar results. A study conducted by Fisher et al. found both cross-sectional and time-concordant relationships between Diabetes Distress with HbA1C. We suspect that each most likely influences the other over time, suggesting a bidirectional relationship. For example, for some patients, high Disease Distress can influence selfmanagement and medication adherence with subsequent effects on glycemic control, and for other patients, poor glycemic control can lead to Distress, which can influence disease management. This formulation of the relationship between Diabetes Distress and glycemic control does not assume the direct involvement of any physiological process but instead emphasizes the ongoing negative subjective experience of emotional Distress around the management of a significant chronic condition that has implications for ongoing disease related behavior, motivation, self-efficacy, and problem solving. Aikens et al. [8] conducted a longitudinal study in which he assessed the patients at baseline and 6 months. He found that Diabetes Distress predicts the glycemic control (p-value<0.001). Diabetes Distress tends to selectively disrupt the activities that are highly specific to Diabetes Mellitus (e.g., taking medication). For example, if the simple act of taking an oral hypoglycaemic drug happens to serve as a frequent and emotionally stressful reminder of negative aspects of having Diabetes Mellitus, then high Diabetes Distress could be expected to reduce treatment adherence. This could explain the observed link between the Diabetes Distress and glycosylated haemoglobin [11].

Similar results were found in a study conducted by Bryan Leyva et al. in which the relative effects of change in Diabetes specific emotional Distress on change in HbA1c in Hispanics with type 2 
Diabetes Mellitus before and after a diabetes selfmanagement education intervention were examined. Change in HbAlc was significantly associated with change in Diabetes Distress among Hispanic patients [12]. In the present study from the baseline to 6 months with the improvement in the Depressive symptoms there was improvement in glycosylated haemoglobin levels. In a meta-analysis conducted by Lustman et al. Depressive Disorder was associated with glycemic control. Depressive Disorder is associated with a decrease in metabolic control, poor adherence to medication and diet regimen, a reduction in quality of life, and an increase in health care expenditures. In turn, poor metabolic control may exacerbate Depressive Disorder and diminish response to antidepressant regimens. Both cognitive behavior therapy and selective serotonin reuptake inhibitors have been associated with glycemic improvement in some studies [13]. In a study conducted by Calhoun et al. a positive relationship was found between the severity of Depressive Disorder and HbA1C levels [14]. Trief et al. found no significant correlation between HbA1C level and Depressive Disorder in his study [15].

Crispin Trebejo B et al. conducted a crosssectional study in which he found that Depressive Disorder increased the probability of poor glycemic control. There was an association between Depressive Disorder and poor glycemic control among type 2 Diabetes Mellitus patients in his study [16]. Our findings were different from the study conducted by Fisher et al. Who in a non-interventional study assessed 506 type 2 Diabetes Mellitus patients at baseline and 9 and 18 months later? He found no concurrent or longitudinal association between Major Depressive Disorder or Depressive symptoms with HbA1C [8].

Diabetes Mellitus and co-morbid Depression has emerged as global emergency. Integration of mental health care and Diabetes Mellitus care is required to combat this situation.

\section{Conclusions}

Better glycemic control improves the Diabetes Distress as well as HAM-D score.

\section{REFFERENCE}

1. IDF. IDF Diabetes Atlas. International Diabetes Federation. 2015: 1-163.

2. World Health Organization. Depression and other common mental disorders: global health estimates. World Heal Organ. 2017: 1-24.

3. Roy T, Lloyd CE. Epidemiology of depression and diabetes: a systematic review. J Affect Disord. 2012;142:S8-21.

4. Nouwen A, Winkley K, Twisk J, Lloyd CE, Peyrot M, Ismail K. Type 2 diabetes mellitus as a risk factor for the onset of depression: a systematic review and meta-analysis. Diabetologia. 2010;53:2480-6.

5. Mezuk B, Eaton WW, Albrecht S, Golden SH. Depression and Type 2 Diabetes Over the Lifespan. Diabetes Care. 2008;31:2383-90.

6. Ascher-Svanum H, Zagar A, Jiang D, Schuster D, Schmitt H, Dennehy EB. Associations Between Glycemic Control, Depressed Mood, Clinical Depression, and Diabetes Distress Before and After Insulin Initiation: An Exploratory, Post Hoc Analysis. Diabetes Ther. 2015;6:303-16.

7. Fisher L, Hessler DM, Polonsky WH, Mullan J. When is diabetes distress clinically meaningful?: establishing cut points for the Diabetes Distress Scale. Diabetes Care. 2012;35:259-64.

8. Fisher L, Mullan JT, Arean P, Glasgow RE, Hessler D, Masharani U. Diabetes distress but not clinical depression or depressive symptoms is associated with glycemic control in both crosssectional and longitudinal analyses. Diabetes Care. 2010;33:23-8.

9. Ramkisson S, Pillay BJ, Sartorius B. Journal of Endocrinology, Metabolism and Diabetes of South Africa Diabetes distress and related factors in South African adults with type 2 diabetes Diabetes distress and related factors in South African adults with type 2 diabetes. J Endocrinol Metab Diabetes South Africa. 2016;21:35-9.

10. Wong EM, Afshar R, Qian H, Zhang M, Elliott TG, Tang TS. Diabetes Distress, Depression and Glycemic Control in a Canadian-Based Specialty Care Setting. Can J Diabetes. 2017;41:362-5.

11. Aikens JE. Prospective associations between emotional distress and poor outcomes in type 2 diabetes. Diabetes Care. 2012;35:2472-8.

12. Leyva B, Zagarins SE, Allen NA, Welch G. The relative impact of diabetes distress vs depression on glycemic control in hispanic patients following a diabetes self-management education intervention. Ethn Dis. 2011;21:322-7.

13. Lustman PJ, Clouse RE. Depression in diabetic patients: The relationship between mood and glycemic control. Journal of Diabetes and its Complications. 2005;19:113-22.

14. Calhoun D, Beals J, Carter EA, Mete M, Welty TK, Fabsitz RR. Relationship between glycemic control and depression among American Indians in the Strong Heart Study. J Diabetes Complications. 2010;24:217-22.

15. Trief PM, Morin PC, Izquierdo R, Teresi J, Eimicke JP, Goland R. Depression and glycemic control in elderly ethnically diverse patients with diabetes: the IDEA Tel project. Diabetes Care. 2006;29:830-5.

16. Crispín-Trebejo B, Robles-Cuadros MC, BernabéOrtiz A. Association between depression and glycemic control among type 2 diabetes patients in Lima, Peru. Asia-Pacific Psychiatry. 2015;7:41926. 